\title{
Estimation of the Frequency of Isoform- Genotype Discrepancies at the Apolipoprotein E Locus in Heterozygotes for the Isoforms
}

\author{
F. Mailly, P. Moll, B.A. Kottke, M.I. Kamboh, S.E. Humphries, \\ and R.E. Ferrell
}

University College and Middlesex School of Medicine, Department of Medicine, The Rayne Institute, London, UK (F.M., S.E.H.), Department of Epidemiology, University of Michigan, Ann Arbor, Michigan (P.M.), Mayo Clinic and Foundation, Rochester, Minnesota (B.A.K.), and Department of Human Genetics, University of Pittsburgh Graduate School of Public Health, Pittsburgh, Pennsylvania (M.I.K., R.E.F.)

Estimates of the impact of apolipoprotein E (apo E) alleles coding for the three common isoforms on plasma lipid levels assume genetic homogeneity among the genotype classes. To test this assumption, we have determined the apo $\mathrm{E}$ genotype at the two common polymorphic sites (amino acids 112 and 158) by DNA amplification and hybridisation with allele-specific oligoprobes, in 195 unrelated Caucasian participants of the Rochester Family Heart Study previously classified as heterozygotes by isoelectric focusing (IEF). Fourteen discordant samples were initially detected. Repeat typing of these samples by both methods resolved nine discrepancies and analysis of additional blood samples from the remaining five individuals eliminated a further four discrepancies. The only truly discordant allele was found in a female subject who had an E3 isoform with the common E2 $\left(\mathrm{Cys}_{112}\right.$, $\mathrm{Cys}_{158}$ ) genotype. Transmission of this allele from the mother was demonstrated. From these results, we estimate the frequency of discrepancies between isoforms and common genotypes to be $0.25 \%$ in this population. Allele misclassification was caused by poor amplification of the DNA in six samples and superimposition of glycosylated and nonglycosylated apo $\mathrm{E}$ isoforms on isoelectric focusing gels in five samples. We conclude that the assumption of genetic homogeneity among genotype classes is valid and that misclassification due to technical difficulties is more frequent than true discordancies. (๑) 1992 Wiley-Liss, Inc.

Received for publication April 7, 1992; revision accepted May 19, 1992.

Address reprint requests to Robert E. Ferrell, PhD, Department of Human Genetics, Graduate School of Public Health, University of Pittsburgh, Pittsburgh, PA 15261.

(C) 1992 Wiley-Liss, Inc. 
Key words: Apolipoprotein E, measured genotype, genetic epidemiology, cardiovascular disease

\section{INTRODUCTION}

Polymorphic allelic variation at the human apolipoprotein $\mathrm{E}$ (apo E) locus is known to have a significant role in determining interindividual variation in plasma levels of apolipoprotein E, apolipoprotein B, total cholesterol, and LDL-cholesterol in the general population [Sing and Davignon, 1985; Davignon et al., 1988; Kaprio et al., 1991; Xhignesse et al., 1991]. These effects have been replicated in a variety of human populations of diverse genetic background exposed to a variety of cultural and dietary environments [Boerwinkle et al., 1987; Sepehmia et al., 1989a]. Apolipoprotein E genetic variation can be detected at the protein level using a variety of electrophoretic techniques [Utermann et al., 1977; Zannis et al., 1981; Bouthillier et al., 1983; Kamboh et al., 1988]. Detection at the DNA level can be achieved by amplification of the DNA segment containing E2/E3 and E3/E4 allelic substitution sites using the polymerase chain reaction (PCR) followed by hybridisation to allele specific oligonucleotides [Funke et al., 1986; Emi et al., 1988; Houlston et al., 1989 Smeets et al., 1988] or digestion with the restriction endonuclease $H$ haI to yield allele specific cleavage patterns [Hixson and Vernier, 1990]. Genetic heterogeneity in the common E2, E3, and E4 phenotypes has been recognized in allele products which give a similar or identical isoprotein pattern as for one of the common alleles. These involve distinct, rare, amino acid substitutions and are frequently associated with familial hyperlipoproteinaemia.

The measured genotype approach used in the estimation of allelic effects associated with the apo E polymorphism assumes allelic homogeneity within phenotype classes. With the exception of the study of Emi et al. [1988], there have been no populationbased studies to estimate the frequency of discrepancies between the isoforms determined by IEF and the genotypes at the apo E locus. In this context, discrepancies refer to alleles giving rise to the protein phenotype of one of the common apo E alleles, but which contain nucleotide substitutions different than those causing the common polymorphism. We have used a combination of protein typing by IEF-immunoblotting and genotyping using the PCR technique followed by hybridization to allele specific oligonucleotides (ASO) to estimate directly the frequency of discrepant alleles occurring in the E2, E3, and E4 isoform classes in a sample of individuals heterozygous for the protein polymorphisms and selected from the general population of Rochestr, MN. In the course of comparing genotype assignments using these two methods, we have identified common sources of error associated with phenotyping and genotyping. The results are discussed in the context of application of the measured genotype approach to the estimation of allelic effects in population samples.

\section{MATERIALS AND METHODS \\ Sample}

All samples for this study were drawn from the Rochester Family Heart Study described by Moll et al. [1989] and Turner et al. [1989]. The Rochester Family Heart Study was designed to evaluate the effects of environment and inherited traits on lipid transport and hypertension. In Janury 1984, we arranged for officials of the school system in Rochester, MN, to send letters to 5,270 households having two or more children enrolled in the city's public and parochial schools. In the letter, we first described 
the purpose of the study and then requested each household willing to consider participation in the study to return an enclosed questionnaire providing information about the household (number of children in the household, projected future length of residence in Rochester, number of grandparents living in the Rochester area), phone number, and address. The questionnaire did not contain any queries regarding disease status or family history of disease. From a total of 1,812 questionnaires that were returned (response rate of $34.4 \%$ ), 159 households were judged unsuitable for sampling either because they (1) did not want to be contacted further $(n=105)$, (2) reported they planned to move from Rochester within 12 months $(n=12)$, (3) reported there were only adopted children in the household $(n=17)$, or $(4)$ gave various other reasons ( $n$ $=25$ ) that participation was unlikely (e.g., unwillingness to visit the clinic or have blood drawn). Between December 1, 1984 and January 1, 1988 we contacted 436 of the 1,653 households eligible for sampling, and 2,004 individuals identified by 300 households agreed to participate and completed a clinic visit. These 2,004 individuals were distributed among 276 pedigrees ranging in size from 1 to 24 (mean 7.3). The study reported here is based on 567 unrelated spouses from these pedigrees who were parents of the index school children.

Among the 567 individuals eligible for the present study, 565 were typed for Apo E. Three were E2/2, 65 were E3/2, 329 were E3/3, 10 were E4/2, 149 were E4/3, and 9 were E4/4. Of the 224 heterozygotes, 195 (58 E3/2, $10 \mathrm{E} 4 / 2$, and 127 E4/3) had both plasma and DNA samples available for the present study and were used to estimate the frequency of discrepancies.

\section{LABORATORY METHODS}

Plasma cholesterol, triglyceride, HDL-cholesterol (HDL-C), and apolipoproteins AI, AII, B, CII, CIII, and E levels were measured as described by Kottke et al. [1991].

Apolipoprotein E phenotypes were determined from frozen EDTA plasma by the isoelectric focusing-immunoblot method of Kamboh et al. [1988] on samples transported on dry-ice. DNA was extracted from peripheral white blood cells by the Triton X-100 lysis method [Kunkel et al. 1977] and sent to London on dry-ice for analysis. Apo E genotypes were determined by direct amplification of a $330 \mathrm{bp}$ region spanning both the E2/E3 and E3/E4 allelic sites (aminio acids 94-203), and detection by hybridisation to end-labelled allele-specific oligonucleotides, following transfer to Hybond-N filters (Amersham), essentially as described by Houlston et al. [1989]. The allele-specific oligoprobes (ASO) were however shortened as follows: $\operatorname{Arg}_{112}, 3^{\prime}$ CCGGCGCGTGCAG-5'; Cys $_{112}, 3^{\prime}$-CCTGCACACGCCGG-5'; Cys ${ }_{158}$, 3'-CGGTCCGCGAAGAC-5'; $\operatorname{Arg}_{158} 3^{\prime}$-CGTCTTCACGGACCG-5'. Hybridisation was carried out at $42^{\circ} \mathrm{C}$ and filters were washed briefly at $49-50^{\circ} \mathrm{C}$. In later experiments, a second $\operatorname{Arg}_{112}$ probe, $3^{\prime}$-GCCGGTGCGTGCAGG-5', containing an additional mismatch at the 6 th nucleotide from the $3^{\prime}$ end ( $\mathrm{T}$ for $\mathrm{C}$ ), was used. The discriminant washing temperature for this probe was $53-54^{\circ} \mathrm{C}$ in $3 \times \operatorname{SSPE}\left(1 \times \mathrm{SSPE}=0.15 \mathrm{M} \mathrm{NaCl}, 0.01 \mathrm{M} \mathrm{NaH}_{2} \mathrm{PO} 4\right.$, 0.001 M EDTA, pH 7.4).

Genotyping was also carried out by amplification of a $216 \mathrm{bp}$ region, again spanning both polymorphic sites (amino acids 104-177), with internal primers (5'CTGGGCGCGGACATGGAGGACGT-3' and 5'-GATGGCGCTGAGGCCGCGCTCG$3^{\prime}$ ), followed by digestion with the restriction enzyme HhaI. Separation of the frag- 
ments was achieved on $8 \%$ polyacrylamide gels (acrylamide:bis, 19:1), run for $3 \mathrm{hr}$ at $35 \mathrm{~mA}$ (constant current) in Tris-borate buffer (0.089 M Tris, $0.089 \mathrm{M}$ boric acid, $0.002 \mathrm{M}$ EDTA).

\section{Statistical Methods}

Statistical tests that gave $P<0.05$ were considered significant unless otherwise denoted. Analysis of variance was used to compare the 195 heterozygotes included in this study with the 29 heterozygotes that were not. Lipids, lipoproteins, and apolipoproteins levels were compared between individuals with discrepant alleles and all other heterozygotes from the Rochester Family Heart Study with the same isoforms (or phenotype). Gender- and phenotype-specific multiple regression was used to estimate the effects of concomitants (date of assay, age, age $^{2}$, height, weight, and smoking) in those without the discrepant alleles. The levels of the traits were then adjusted for variability in concomitants for all of the individuals with the same gender and phenotype (both with and without the discrepant alleles) using these regression equations. Percentiles were calculated for the individuals with the discrepant alleles.

\section{RESULTS}

The distribution of age, measures of body size, lipids, lipoproteins, and apolipoproteins for the heterozygous individuals used in this study are described in Table I for the 91 males and 104 females. When the 195 heterozygotes included in this study were compared to the 29 heterozygotes not included, there were no differences in the mean levels of any traits considered or in the relative frequency of males (data not shown).

Biochemical and molecular analysis of 195 unrelated individuals heterozygous for apo $\mathrm{E}$ phenotypes by isoprotein typing revealed a number of inconsistent phenotypes, as shown in Table II. Among the 14 inconsistent phenotypes, five were resolved by repeat isoprotein typing (two on the redrawn sample), six were resolved by repeat ASO analysis, two were found to be due to sample mislabelling and were resolved by resampling of the individuals involved, and one was found to represent a true discrepancy. Thus, this analysis detected one discrepant allele among the 195 individuals tested,

TABLE I. Description of 195 Subjects

\begin{tabular}{lrrrr} 
& \multicolumn{3}{c}{ Mean (SD) } \\
\cline { 2 - 6 } Trait & Females & $(n=104)$ & Males & $(n=91)$ \\
\hline Age (years) & 41.2 & $(6.3)$ & 43.5 & $(6.9)$ \\
Height (cm) & 164.8 & $(6.1)$ & 178.2 & $(6.1)$ \\
Weight (kg) & 68.9 & $(13.7)$ & 85.4 & $(12.8)$ \\
Chol (mg/dl) & 179.7 & $(36.8)$ & 190.0 & $(39.7)$ \\
Trigs (mg/dl) & 111.1 & $(68.9)$ & 163.0 & $(108.9)$ \\
HDL-C (mg/dl) & 50.0 & $(13.0)$ & 39.6 & $(10.2)$ \\
Apo AI (mg/dl) & 140.1 & $(18.7)$ & 130.4 & $(15.8)$ \\
Apo AIl (mg/dl) & 34.2 & $(4.9)$ & 33.5 & $(4.5)$ \\
Apo B (mg/dl) & 75.6 & $(15.3)$ & 80.0 & $(14.4)$ \\
Apo CII (mg/dl) & 2.0 & $(0.8)$ & 2.7 & $(1.0)$ \\
Apo E (mg/dl) & 4.4 & $(1.9)$ & 5.5 & $(4.3)$ \\
\hline
\end{tabular}


TABLE II. Apo E Genotype-Phenotype Discrepancies and Partial Resolution Following Retyping of Original Samples and Typing of Redraw Samples

\begin{tabular}{|c|c|c|c|c|c|c|c|c|}
\hline Sample & $\begin{array}{l}\text { First } \\
\text { protein } \\
\text { typing } \\
\end{array}$ & $\begin{array}{l}\text { First } \\
\text { DNA } \\
\text { typing }\end{array}$ & $\begin{array}{l}\text { Second } \\
\text { protein } \\
\text { typing - } \\
\text { original } \\
\text { samples }\end{array}$ & $\begin{array}{l}\text { Second } \\
\text { DNA } \\
\text { typing - } \\
\text { original } \\
\text { samples } \\
\end{array}$ & $\begin{array}{l}\text { Third } \\
\text { protein } \\
\text { typing - } \\
\text { redraw } \\
\text { samples }\end{array}$ & $\begin{array}{l}\text { Third } \\
\text { DNA } \\
\text { typing - } \\
\text { redraw } \\
\text { samples }\end{array}$ & Status & $\begin{array}{l}\text { Probable } \\
\text { cause of } \\
\text { discrepancy }\end{array}$ \\
\hline 288 & $4 / 3$ & $3 / 3$ & $4 / 3$ & $4 / 3$ & - & - & Resolved & $\mathrm{PA}^{\mathrm{a}}$ \\
\hline 296 & $3 / 2$ & $3 / 3$ & $3 / 2$ & $3 / 2$ & - & - & Resolved & PA \\
\hline 330 & $4 / 3$ & $3 / 3$ & $4 / 3$ & $4 / 3$ & - & - & Resolved & PA \\
\hline 575 & $4 / 3$ & $4 / 4$ & $4 / 4$ & $4 / 4$ & - & - & Resolved & $\mathrm{SGI}^{\mathbf{b}}$ \\
\hline 589 & $4 / 3$ & $3 / 3$ & $3 / 3$ & $3 / 3$ & - & - & Resolved & $?^{c}$ \\
\hline 1068 & $3 / 2$ & $4 / 2$ & $3 / 2$ & $3 / 2$ & - & - & Resolved & PA \\
\hline 1096 & $4 / 2$ & $4 / 3$ & $4 / 3$ & $4 / 3$ & - & - & Resolved & SGI \\
\hline 1651 & $3 / 2$ & $4 / 2$ & $3 / 2$ & $3 / 2$ & - & - & Resolved & PA \\
\hline 1843 & $3 / 2$ & $4 / 2$ & $3 / 2$ & $3 / 2$ & - & - & Resolved & PA \\
\hline 499 & $4 / 2$ & $3 / 3$ & $4 / 2$ & $3 / 3$ & $4 / 2$ & $4 / 2$ & Resolved & Sample mix \\
\hline 1084 & $3 / 2$ & $2 / 2$ & $ـ^{d}$ & $2 / 2$ & $2 / 2$ & $2 / 2$ & Resolved & Sample mix \\
\hline 1612 & $3 / 2$ & $3 / 3$ & $3 / 2$ & $3 / 3$ & $3 / 3$ & $3 / 3$ & Resolved & SGI \\
\hline 1622 & $3 / 2$ & $4 / 3$ & $3 / 2$ & $3 / 3$ & $3 / 3$ & $3 / 3$ & Resolved & SGI \\
\hline 631 & $3 / 2$ & $2 / 2$ & $3 / 2$ & $2 / 2$ & $3 / 2$ & $2 / 2$ & Unresolved & Mutation \\
\hline
\end{tabular}

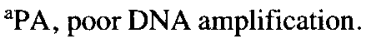

bSI, superimposition of glycosylated isoform.

${ }^{c}$ Cause of inconsistency unknown.

dSample not available.

an E3 allele at the protein level which was a common E2 $\left(\mathrm{Cys}_{112}, \mathrm{Cys}_{158}\right)$ at the gene level, for an overall frequency of approximately $0.25 \%$. Subject 631 was heterozygous by isoprotein typing (E3/2) was apparently homozygous by ASO analysis (E2/2). To confirm the genotyping, DNA fragments were amplified spanning the region of the apo $\mathrm{E}$ gene coding for amino acids 104-177, the DNA digested with the enzyme HhaI, and the size of the resulting fragments analysed by polyacrylamide gel electrophoresis. The pattern of fragments seen was as expected for their ASO genotype. DNA and plasma samples were available for analysis for family members of the individual carrying a discrepant allele, and the results and pedigree ascertained through household 1749 are shown in Figure 1. The proband's mother also showed the same discrepancy, having an allele which behaved as an E3 allele on isoelectric focusing but appeared as an E2 allele by ASO typing, but neither of the children of the proband inherited the discrepant allele.

\section{Description of Subjects With Discrepant Alleles}

A description of the individual and her mother with a discrepant allele is presented in Table III. Based on the physical examination data and medical record review, subject 631 had fasted, had never smoked, and did not report the use of any medications in the 2 months prior to the study. In 1980, she was diagnosed with mitrial prolapse at the Mayo Clinic. Otherwise she was considered not to have any other cardiovascular disease, was normotensive, and had had four normal ECGs. Her trait levels, after adjustment for concomitants, placed her above the 95th percentile for HDL-C and below the 5th percentile for apolipoprotein B compared to all other females in the 
POCHESTER FAMILY HEART STUDY - HOUSEHOLO 1749

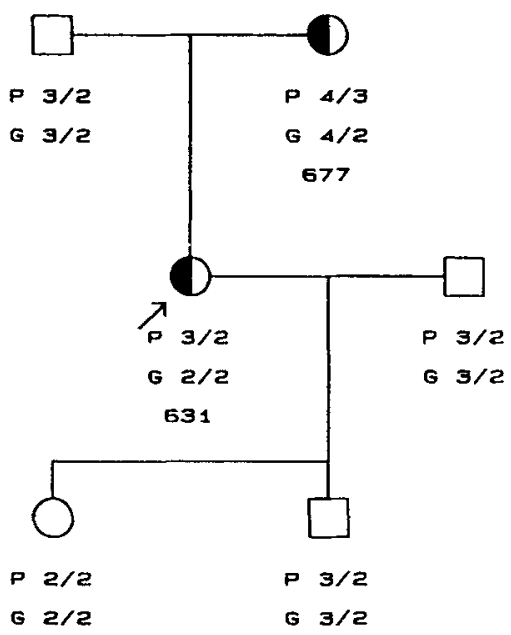

P: PHENOTYPE

1749

Fig. 1. Segregation of the apo E protein isoform and DNA genotypes in individuals ascertained through household number 1749 . The numbers below the genotypes $(631,677)$ are the individuals identification number, as referred to in the text.

Rochester Family Heart Study with the E3/2 phenotype. She was close to the 90 th percentile for plasma levels of both apolipoprotein AI and apolipoprotein E.

The mother of this individual (subject 677) had fasted, had never smoked, and was overweight. She had been diagnosed 10 years earlier with hypertension and all her ECGs had been normal. She reported taking a diuretic, a calcium supplement, a potassium supplement, and replacement estrogen in the 2 months prior to the study. After adjustment for concomitants, she was above the 98th percentile for triglycerides when compared to all other E4/3 females in the Rochester Family Heart Study. She was above the 95th percentile for apolipoprotein CIII and above the 90th for both apolipoprotein AII and CII. Only apolipoprotein B was below the 50th percentile.

\section{DISCUSSION}

A useful approach to the study of quantitative traits associated with risk of common disease is to characterize the association between allelic variation at candidate gene or random marker loci and quantitative trait levels [Boerwinkle et al., 1986]. The measured genotype approach has proven to be usefeul for estimating the impact of specific alleles on quantitative traits in samples from the general population. This approach has demonstrated a significant contribution of allelic variation at the apolipoprotein $\mathrm{E}$ locus in determining plasma levels of apo E, apo B, LDL-cholesterol, and total cholesterol in a number of populations [Sing and Davignon, 1985; Boerwinkle 
TABLE III. Description of the Proband and One Relative With Discrepant Alleles (Percentile Compared to Other Females of Same Phenotype After Adjustment for Concomitants)

\begin{tabular}{|c|c|c|c|c|}
\hline & \multicolumn{2}{|c|}{ Proband } & \multicolumn{2}{|c|}{ Mother } \\
\hline Identification No. & \multicolumn{2}{|c|}{631} & \multicolumn{2}{|c|}{677} \\
\hline Household & \multicolumn{2}{|c|}{1749} & \multicolumn{2}{|c|}{1749} \\
\hline \multicolumn{5}{|l|}{ Trait } \\
\hline Gender & \multicolumn{2}{|c|}{ Female } & \multicolumn{2}{|c|}{ Female } \\
\hline Age (years) & \multicolumn{2}{|c|}{35.7} & \multicolumn{2}{|c|}{62.4} \\
\hline Height $(\mathrm{cm})$ & \multicolumn{2}{|c|}{162.4} & \multicolumn{2}{|c|}{161.2} \\
\hline Weight (kg) & \multicolumn{2}{|c|}{55.4} & \multicolumn{2}{|c|}{82.5} \\
\hline Cholesterol $(\mathrm{mg} / \mathrm{dl})$ & 149.0 & $(18.3 \%)$ & 237.0 & $(74.2 \%)$ \\
\hline Triglycerides (mg/dl) & 82.0 & $(43.1 \%)$ & 405.0 & $(98.8 \%)$ \\
\hline HDL-C (mg/dl) & 79.0 & $(96.3 \%)$ & 49.0 & $(59.5 \%)$ \\
\hline Apo AI (mg/dl) & 170.0 & $(89.9 \%)$ & 163.0 & $(86.1 \%)$ \\
\hline Apo AII (mg/dl) & 41.1 & $(79.8 \%)$ & 40.3 & $(91.3 \%)$ \\
\hline Apo B (mg/dl) & 51.0 & $(3.7 \%)$ & 84.0 & $(31.1 \%)$ \\
\hline Apo CII (mg/dl) & 2.3 & $(51.3 \%)$ & 4.1 & $(90.8 \%)$ \\
\hline Apo CIII (mg/dl) & 18.0 & $(79.8 \%)$ & 25.5 & $(95.6 \%)$ \\
\hline Apo E (mg/dl) & 8.1 & $(89.0 \%)$ & 5.3 & $(62.7 \%)$ \\
\hline
\end{tabular}

and Sing, 1987; Boerwinkle et al., 1987; Davignon et al., 1988; Kaprio et al., 1991]. Additionally, it has been used to examine the impact of genetic variation at a variety of loci coding for genes that are directly involved in lipid metabolism on quantitative lipoprotein lipid traits [Sepehrnia et al., 1989b]. The measured genotype approach assumes allelic homogeneity. If heterogeneity exists, then the interpretation of the estimated allelic effects could be biased. The definition of what constitutes similar alleles would affect the estimate itself. Variability between subgroups with respect to the frequency of and variability in discrepant alleles could impact the interpretation of comparison between presumed genotype classes.

Initially, we identified 14 inconsistencies between phenotype and genotype. Six of these were due to technical difficulties with the ASOs used. Poor amplification of DNA, which occurs with some samples possibly because of contamination with salt during the preparation, resulted in a poor discrimination between the signal seen with the $\mathrm{Cys}_{112}$ probe and the $\mathrm{Arg}_{112}$ probe. This was resolved on a second amplification and by the use of an ASO with an additional mismatched base which enabled the different washing conditions used to be more effective. The major source of discrepancy for protein typing (four samples) appears to be due to the glycosylation of apo $\mathrm{E}$ isoforms. The electrophoretic patterns of apolipoprotein $E$ isoforms on IEF gels are a direct result of charge variations dependent on both genetic variation at the apolipoprotein $E$ gene locus, and posttranslational modification effects which cause a shift in isoform mobility [Zannis and Breslow, 1981]. This in turn results in the superimposition of glycosylated and nonglycosylated forms in heterozygotes. Recently, Snowdon et al. [1991] have reported that diabetic subjects, which have a 2 - to 10 -fold increase in protein glycosylation, show a disparity between the apo $\mathrm{E}$ allelic frequencies obtained by protein and DNA typing. Therefore, it is likely that differences in the level of glycosylation, determined in part by the plasma glucose level, explain some of the inconsistencies. In particular, individual 1622 , initially E3/2 at the protein level but with an E3/3 genotype, had elevated plasma glucose (97\% percentile compared with other E3/2 RFHS individuals after adjustment for concomitants). Alternatively, the amount of protein 
loaded on the gels for these individuals might influence the typing. Another possible source of error, not encountered in this study, is that lipoproteins with the apo E4 protein are known to have a faster metabolic rate, and are cleared rapidly from the circulation. This causes a low plasma concentration of the apo E4 isoform which therefore may escape detection.

It is of interest that of the original 14 inconsistencies between phenotype and genotype, only one involved an individual with a truly discrepant allele. Two could only be resolved by obtaining new samples from the participants due to an error in sample labeling. This represents a laboratory misidentification rate of approximately $1 \%$ ( 2 of 194 if excluding the individual with a true discrepant allele). Of the remaining 11 inconsistencies, 6 samples were incorrect for only the first DNA typing, 4 samples were incorrect for only the first protein typing, and one sample was incorrect for both the first typings. We estimate the sample error rates to be approximately $3.6 \%$ for the DNA typing ( 7 of 192) and 2.6\% (5 of 192) for the protein typing. Both of these error rates are 2 to 3 times higher than the relative frequency of errors in sample identification and at least 5 times higher than the relative frequency of individuals with discordant alleles in this study. Based on these data, laboratory errors in typing for apo $\mathrm{E}$ have the potential to contribute more to bias in measured genotype studies than sample identification errors or discordant alelles for apo E heterozygotes.

Apolipoprotein and lipoprotein levels in the two individuals identified in this study as carrying a discordant allele were not indicative of the lipoprotein profile associated with Type III hyperlipoproteinaemia. This disorder, characterized by hypercholesterolaemia, hypertriglyceridaemia, remnant lipoproteins, and the E2/2 phenotype, has been the basis of identifying variant apo $\mathrm{E}$ alleles in a number of studies. However, the discordant allele may be involved in the development of hyperlipidaemia. While individual 631 had very low lipid levels, characteristic of normolipidemic individuals with the E2/2 phenotype, her mother was clearly hypertriglyceridemic. Drawing a parallel with type III, it is possible that their apo E genotypes predisposes them to this phenotype but that an additional factor, such as obesity, is needed to cause hyperlipidemia. Although we have not attempted the further molecular characterization of this mutant allele, the presence of E2-Christchurch in these individuals can be ruled out as this mutation would have been revealed by the cleavage pattern with HhaI.

The results presented here support the assumption of near homogeneity within the three heterozygous apo E genotype classes in Caucasian populations, with an estimated frequency of discrepancies of less than $1 \%$. This is very likely to represent an underestimate as neutral amino acid substitutions, which are expected to be more frequent, were not accounted for by the methodology used. However, the methodological problems outlined above may still be proportionately much more important for the misclassification of individuals. We cannot rule out that a discrepant allele could have been missed although this is less likely since the inheritance of apo $E$ alleles was checked in the families of all the subjects involved in this study. The results are nevertheless consistent with the estimate of $2 \%$ (two variant alleles among 100 alleles tested) seen by Emi et al. [1988] in the Caucasian population of Utah. Whether this estimate applies to non-Caucasian populations and whether population differences in the frequency of apo $E$ variant alleles contributes to differences in estimated allelic effects in some populations, remains to be determined. 


\section{ACKNOWLEDGMENTS}

This work was supported by NIH Grant 5 RO1 HL 39107-03, Grants HL24489 and HL30428, by the Charing Cross Sunley Research Trust, and Grants from the British Heart Foundation (RG5). France Mailly is the recipient of a Research Traineeship from the Canadian Heart and Stroke Foundation. We thank Dr. Charles F. Sing for his constructive comments on this manuscript.

\section{REFERENCES}

Boerwinkle E, Chakraborty R, Sing CF (1986): The use of measured genotype information in the analysis of quantitative phenotypes in man. I. Models and analytical methods. Ann Hum Genet 50:181-194.

Boerwinkle E, Sing CF (1987): The use of measured genotype information in the analysis of quantitative phenotypes in man. III. Simultaneous estimation of the frequencies and effects of the apolipoprotein E polymorphism and residual polygenic effects on cholesterol betalipoprotein and triglyceride levels. Ann Hum Genet 51:211-226.

Boerwinkle E, Visvikis S, Welsh D, Steinmetz J, Hanash S, Sing CF (1987): The use of measured genotype information in the analysis of quantitative phenotypes in man. II. The role of apolipoprotein $\mathrm{E}$ polymorphism in determining levels, variability and covariability of cholesterol, betalipoprotein and triglyceride levels in a sample of unrelated individuals. Am J Med Genet 27:567-582.

Bouthillier D, Sing CF, Davignon J (1983): Apolipoprotein E phenotyping with a single gel method-application to the study of informative matings. J Lipid Res 24:1060-1069.

Davignon J, Gregg RE, Sing CF (1988): Apolipoprotein E polymorphism and atherosclerosis. Arteriosclerosis $8: 1-21$.

Emi M, Wu LL, Robertson MA, Myers RL, Hegele RA, Williams RR, White R, Lalouel JM (1988): Genotyping and sequence analysis of apolipoprotein E isoforms. Genomics 3:373-379.

Funke H, Rust S, Assmann G (1986) Detection of apolipoprotein E variants by an oligonucleotide "melting" procedure. Clin Chem 32:1285-1289.

Hixson JE, Vernier DT (1990): Restriction isotyping of human apolipoprotein E by gene amplification and cleavage with HhaI. J Lipid Res 31:545-548.

Houlston RS, Snowden C, Green F, Alberti KGMM, Humphries SE (1989): Apolipoprotein E genotypes by polymerase chain reaction and allele-specific oligonucleotide probes: No detectable linkage disequilibrium between apo $\mathrm{E}$ and apo CII. Hum Genet 83:364-368.

Kamboh MI, Ferrell RE, Kottke B (1988): Genetic studies of human apolipoproteins. V. A novel rapid procedure to screen apolipoprotein E polymorphism. J Lipid Res 29:1535-1543.

Kaprio J, Ferrell RE, Kottke BA, Kamboh MI, Sing CF (1991): Effects of polymorphisms in apolipoprotein $\mathrm{E}, \mathrm{A}-\mathrm{IV}$, and $\mathrm{H}$ on quantitative traits related to risk for cardiovascular disease. Arteriosclerosis Thrombosis 11:1330-1348.

Kottke BA, Moll PP, Michels VV, Weidman WH (1991): Levels of lipids, lipoproteins and apolipoproteins in a defined population. Mayo Clinic Proc 66:1198-1208.

Kunkel LM, Smith KD, Boyer SH, Borgaonkar DS, Wachtel SS, Miller OJ, Beg WR, Jones HW, Rary JM (1977): Analysis of human Y-chromsome specific reiterated DNA in chromosome variants. Proc Natl Acad Sci USA 74:1245-1249.

Moll P, Michels V, Weidman W, Kottke BA (1989): Genetic determination of plasma apolipoprotein AI in a population-based sample. Am J Hum Genet 44:124-139.

Sepehrnia B, Kamboh MI, Adams-Campbell LL, Bunker CH, Nwankwo M, Majumder PP, Ferrell RE (1989a): Genetic studies of human apolipoproteins. X. The effect of the apolipoprotein E polymorphism on quantitative levels of lipoproteins in Nigerian blacks. Am J Hum Genet 45:586-591.

Sepehrnia B, Kamboh MI, Adams-Campbell LL, Bunker CH, Nwankwo M, Majumder PP, Ferrell RE (1989b): Genetic studies of human apolipoproteins. XI. The effeect of the apolipoprotein C-II polymorphism on lipoprotein levels in Nigerian blacks. J Lipid Res 30:1349-1354.

Sing CF, Davignon J (1985) Role of apolipoprotein E polymorphisms in determining normal plasma lipid and lipoprotein variation. Am J Hum Genet 37:268-285.

Smeets HJM, Poddighe J, Stuyt PMJ, Stalenhoef AFH, Rogers HH, Wieringa B (1988): Identification of apolipoprotein E polymorphism by using synthetic oligonucleotides. J Lipid Res 29:1231-1237. 


\section{Mailly et al.}

Snowden CS, Houlston RS, Arif MH, Laker MF, Humphries SE, Alberti KG (1991): Disparity between apo $E$ genotypes and phenotypes in patients with diabetes mellitus. Clin Chim Acta 196:49-57.

Turner S, Weidman W, Michels V, Reed T, Ormson C, Fuller T, Sing CF (1989): Distribution of sodiumlithium countertransport and blood pressure in caucasians five to eighty-nine years of age. Hypertension 13:378-391.

Utermann G, Hees M, Steinmetz A (1977): Polymorphism of apolipoprotein E and occurrence of dysbetalipoproteinaemia in man. Nature (London) 269:604-607.

Xhignesse M, Lussier-Cacan S, Sing CS, Kessling AM, Davignon J (1991): Influences of common variants of apolipoprotein $\mathrm{E}$ on measures of lipid metabolism on a sample selected for health. Arteriosclerosis Thrombosis 11:1100-1110.

Zannis VI, Breslow JL (1981): Human very low density lipoprotein apolipoprotein E isoprotein polymorphisms explained by genetic variation and post-translational modification. Biochemistry 20:1033-1041.

Zannis VI, Just PW, Breslow JL (1981): Human apolipoprotein E isoprotein subclasses are genetically determined. Am J Hum Genet 33:11-24.

Edited by Aravinda Chakravarti 